\title{
Argumentation et discours politique. Antiquité grecque et latine, Révolution française, Monde contemporain
}

\section{Raymonde Monnier}

\section{(2) OpenEdition \\ Journals \\ Édition électronique \\ URL : https://journals.openedition.org/ahrf/1558 \\ DOI : 10.4000/ahrf.1558 \\ ISSN : 1952-403X \\ Éditeur : \\ Armand Colin, Société des études robespierristes}

Édition imprimée

Date de publication : 1 septembre 2004

Pagination : 212-213

ISSN : 0003-4436

\section{Référence électronique}

Raymonde Monnier, "Argumentation et discours politique. Antiquité grecque et latine, Révolution française, Monde contemporain », Annales historiques de la Révolution française [En ligne], 337 | juilletseptembre 2004, mis en ligne le 15 février 2006, consulté le 23 avril 2022. URL : http:// journals.openedition.org/ahrf/1558; DOI : https://doi.org/10.4000/ahrf.1558

Ce document a été généré automatiquement le 23 avril 2022.

Tous droits réservés 


\title{
Argumentation et discours politique. Antiquité grecque et latine, Révolution française, Monde contemporain
}

\author{
Raymonde Monnier
}

\section{RÉFÉRENCE}

Simone Bonnafous, Pierre Chiron, Dominique Ducard, Carlos Levy (dir.), Argumentation et discours politique. Antiquité grecque et latine, Révolution française, Monde contemporain, Rennes, Presses Universitaires de Rennes, Collection res publica, 2003, 275 p., ISBN 2-86847-827-1, 19 e.

1 Ce livre, qui témoigne de l'intérêt porté au discours politique et aux études rhétoriques, réunit les actes du colloque de Cerisy-la-Salle de septembre 2001, qui a permis de confronter les recherches conduites ces quinze dernières années par des équipes de sociologues, d'historiens et de linguistes. Ce colloque consacré à l'argumentation politique, organisé en commun par un spécialiste de rhétorique grecque, un latiniste philosophe, un linguiste et une spécialiste de la communication, a réuni des contributions très diverses qui traitent aussi bien de l'Antiquité classique que du monde contemporain. On constate à la lecture des divers auteurs, que les Anciens demeurent une source d'inspiration vivante dans l'étude du discours contemporain, non pour orner le propos mais aussi pour fonder les analyses, ce qui semble parfaitement logique, même si les études historiques ont eu souvent tendance à opposer les Anciens et les Modernes. Le plan de l'ouvrage s'organise autour des grandes questions qui fédèrent ces recherches et les mettent en résonance par delà les siècles, les disciplines et les méthodes. Une première partie s'interroge sur le genre, les normes et l'adaptation des modèles du discours politique. Dans un deuxième temps, les auteurs évaluent la part de mise en scène et de théâtralité au sein du dispositif dans lequel il 
s'incarne. Comment tracer les frontières entre argumentation et manipulation est ce qui fait l'objet de la troisième partie, tandis que la quatrième séquence s'interroge sur les relations entre le discours et la violence qu'il est censé canaliser. Enfin deux communications font le point sur un lieu commun de l'Antiquité et de la période contemporaine, celui de la dégénérescence du discours politique. Un index des noms propres est particulièrement bien venu pour un ensemble aussi riche que divers.

2 Très peu de communications traitent directement du discours politique de la période révolutionnaire, en dehors de celle d'Aurélien Principato sur Madame de Staël et Benjamin Constant, deux auteurs qui considèrent que la communication des idées dans l'espace public révolutionnaire a été une arme à double tranchant, mais qui n'en défendent pas moins la libre discussion. D'autres textes, bien que traitant d'époques plus ou moins éloignées, renvoient à des problématiques qui intéresseront les historiens de la Révolution française, comme celui d'Antonio Ruiz Castellanos sur les constantes rhétoriques du discours nationaliste, ou celui de Bernard Lamizet sur la représentation théâtrale comme moyen de redécouvrir dans la distanciation la force de l'argumentation politique. Je citerai particulièrement la contribution de Dominique Ducard qui s'interroge sur l'existence de formes linguistiques de la manipulation dans le débat parlementaire, à partir de la figure rhétorique de l'interrogation. Ce qui donne lieu à une analyse fine des voies du procédé stratégique de la question biaisée, qui introduit dans l'interrogation, par l'usage du négatif ou autre, une prédétermination de la valeur à reconnaître comme la bonne valeur. À l'aune de la confrontation rationnelle des arguments (Habermas) dans le discours politique, la question rhétorique apparaît comme une figure propre à faire valoir sa propre conviction contre celle de l'autre, tout en se situant dans l'espace intersubjectif de la discussion, même biaisée. En conclusion à ces réflexions qui tentent de jeter un pont entre la tradition rhétorique et les théories contemporaines du discours et de la communication, Maurice Tournier propose quelques définitions sur les espaces. Celui de la communication politique serait défini, dans les termes d'Habermas, "comme le champ d'expression régulé d'un agir communicationnel fondamental et pérenne, pris aux pièges de l'agir stratégique et de l'agir dramaturgique» (p. 262). L'art politique consiste dans l'appropriation des symboles qui forment les langages médiateurs de l'espace public, et s'effectue aux trois niveaux de la parole (prendre la parole), de la langue (l'outil de l'intercompréhension) et des langages eux-mêmes, car il ne suffit pas de parler ni même de parler bien. Dans l'espace de l'argumentation politique, les multiples domaines de l'expression peuvent être mis à contribution : argumenter pour persuader est une opération synthétique de grande ampleur où l'analyste sélectionne, comme chacun dans ce livre, tel aspect syntaxique, discursif ou autre, le choix des mots, des gestes et des images, afin de débusquer les complices de l'agir et du pouvoir communicationnels. 